\title{
Optimization of several surface treatment processes for alleviating fretting damage of a locking pin
}

\author{
Jifan HE ${ }^{1}$, Zhenbing CAI ${ }^{1, *}$, Yanping REN ${ }^{1}$, Jinfang PENG ${ }^{2}$, Jianhua LIU $^{3}$, Minhao ZHU $^{3, *}$ \\ ${ }^{1}$ School of Mechanical Engineering, Southwest Jiaotong University, Chengdu 610031, China \\ ${ }^{2}$ Traction Power State Key Laboratory, Southwest Jiaotong University, Chengdu 610031, China \\ ${ }^{3}$ School of Materials Science and Engineering, Southwest Jiaotong University, Chengdu 610031, China \\ Received: 05 February 2021 / Revised: 28 April 2021 / Accepted: 17 May 2021 \\ (C) The author(s) 2021.
}

\begin{abstract}
The operational safety and reliability of a variable gauge train are affected by the anti-fretting wear performance of the locking mechanism. The main purpose of this study is to optimize the surface treatment process for a locking pin material under actual service conditions to alleviate fretting damage. Based on the two basic principles of surface strengthening and friction reduction, a substrate (AISI 4135 steel) surface was treated by laser quenching (LQ), plasma nitriding (PN), and bonded $\mathrm{MoS}_{2}$ coating. Systematic fretting wear tests were conducted, and the wear behavior and damage mechanism of various treated surfaces were comprehensively investigated. The results indicate that the wear resistances of the LQ- and PN-treated surfaces were significantly improved, and their main wear mechanisms were abrasive wear, delamination, and oxidation wear. The $\mathrm{MoS}_{2}$ coating exhibits the lowest friction coefficient and energy dissipation due to its self-lubricating property, but it incurs the highest wear rate and failure in the form of plastic deformation. Furthermore, the rough compound layer with a high hardness on the PN-treated surface is conducive to the formation and maintenance of the third-body contact at the fretting interface, consequently resulting in a significant reduction in wear. An optimal surface treatment process for alleviating fretting damage of the locking pin is recommended via comprehensive evaluation, which provides a reference for the anti-fretting protection of related mechanical components.
\end{abstract}

Keywords: locking pin; fretting wear; surface treatment; dynamic response; wear mechanism

\section{Introduction}

Railways, as the most widely used type of land transportation, play a crucial role in promoting the development of economies and trade worldwide [1]. The existence of various types of rail gauges in different countries and regions has hampered further improvements in the comprehensive efficiency of railway transport. However, the emergence of variable gauge trains has considerably solved this problem. At present, multiform variable gauge trains have been produced and put into service around the world [2], and China has developed a high-speed variable gauge bogie system (see Fig. 1(a)) for the 1,435/1,520 mm gauge switch. As one of the key components of the bogie, the locking mechanism (as shown in Fig. 1(b)) has the function of a wheel track switch and mechanical locking, and its running reliability strongly determines the safe operation of the trains. During the process of wheel track switching, the locking pin will be jacked up by a ramp track (the spring will be compressed), and will be separated from the matching locking block. Meanwhile, the wheels will be driven by the guiding device to move along the axle to a prescribed gauge. Thereafter, the bogie will be moved away from the ramp, the spring will be reset to make

* Corresponding authors: Zhenbing CAI, E-mail: caizb@swjtu.cn; Minhao ZHU, E-mail: zhuminhao@home.swjtu.edu.cn 

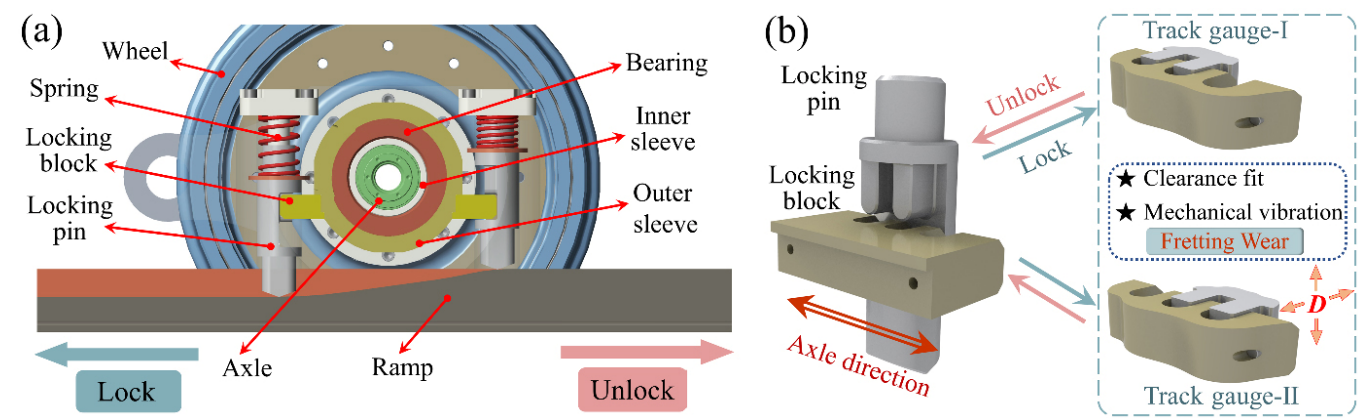

Fig. 1 Diagrams of (a) bogie structure for variable gauge train and (b) service conditions of the locking mechanism.

the locking pin and the locking block re-engage in another position. However, given the clearance fit of the locking mechanism and the alternating loads due to mechanical vibration during the running process, the fretting damage [3-5] always occurs on the matching tooth surface of the locking pin. Based on the actual operating conditions of a train and the relevant standards $[6,7]$, the lateral load applied on the locking mechanism can reach $65.6 \mathrm{kN}$ when the variable gauge train is running along a curve. As shown in Fig. 2, the maximum contact stress $(601.9 \mathrm{MPa})$ on the contact surface of the locking pin is obtained by finite element analysis. Moreover, as the relative slip components Cslip1 (longitudinal) and Cslip2 (lateral) of the mating interface at each node are extracted, the total relative slip of each unit is calculated and the maximum value is $100 \mu \mathrm{m}$. Studies have confirmed that the fretting damage in the key mechanical structures of the bogie strongly threatens the safety of the high-speed trains $[8,9]$. Therefore, to ensure the operational reliability of the locking mechanism, it is crucial to implement surface engineering design of the friction pair material and perform research on the fretting wear behavior under actual service conditions.

The locking pin is made of AISI 4135 steel (similar to $35 \mathrm{CrMo}$ steel), which is a common engineering material and has been widely used in various mechanical components due to its excellent mechanical properties. The researches on fretting wear mechanism for the kind of alloy steels under various factors provide lots of knowledge of the anti-fretting protection for the locking mechanism [10-12]. Among the various measures to alleviate fretting damage [13], surface modification as an efficient and economical solution has been widely used in the industrial field [14, 15]. In this study, optimizing a suitable surface treatment method is essential to protect the locking pin from fretting damage.

In numerous surface modification methodologies, plasma nitriding $(\mathrm{PN})$ as a thermochemical diffusion process, has the advantages of low cost, friendly environment, and excellent wear resistance. The surface hardness of ferrite steel has been found to increase significantly after PN-treated, yielding $\varepsilon-\mathrm{Fe}_{2-3} \mathrm{~N}$ and $\gamma^{\prime}-\mathrm{Fe}_{4} \mathrm{~N}$ phases [16, 17]. Meanwhile, PN treatment of different engineering materials has been proven to enhance fatigue properties $[18,19]$ and to reduce (a)

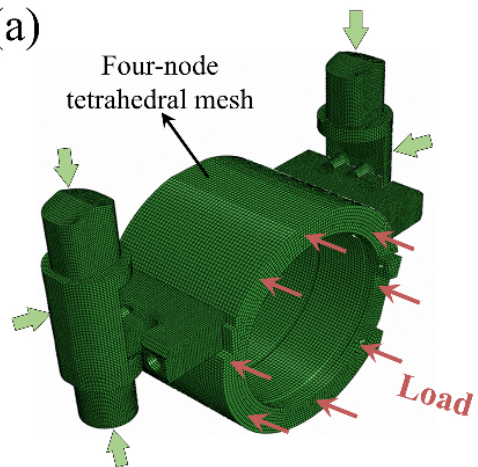

(b)

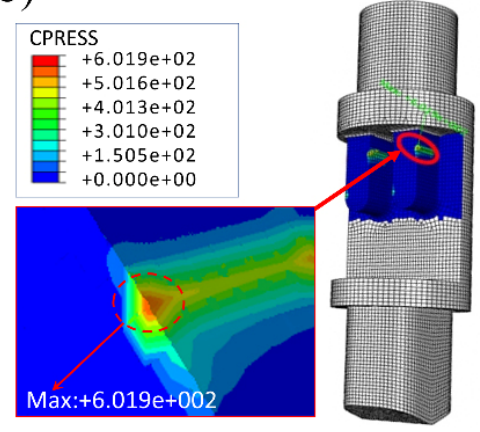

(c)

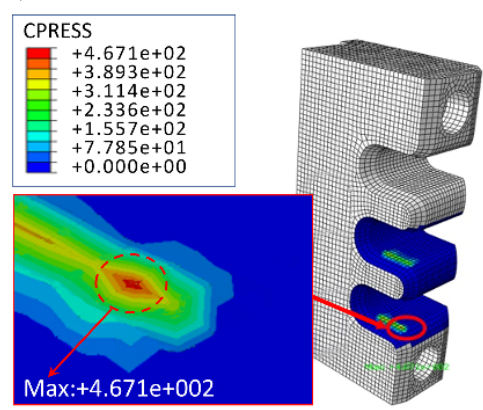

Fig. 2 (a) Finite element model of the locking mechanism and maximum contact stresses of (b) locking pin and (c) locking block. 
surface wear [20-22]. Moreover, laser quenching (LQ), as an economical and efficient surface heat treatment, is a rapid austenitizing process [23]. The martensite structure generated by LQ treatment significantly enhances the hardness and strength of a substrate surface, and a residual compressive stress layer is also beneficial for resisting fretting wear [24, 25]. According to the research of Wang et al. [26], the wear resistance of railway wheel-rail material improved after LQ treatment, and the wear volumes of the wheel and rail materials were reduced by $92.9 \%$ and $80 \%$, respectively. Lesyk et al. [27] proved that diode laser heat treatment enhanced the hardness and wear resistance of tool steel. In addition, in contrast to the method of improving the surface strength and hardness, solid lubricant coatings have also been proven to effectively reduce material wear owing to their antifriction effect $[28,29]$. Luo et al. [30, 31] conducted detailed studies on the wear behavior of $\mathrm{MoS}_{2}$ coating in the form of torsion and rotational fretting wear and confirmed that the solid lubricant coating could alter the fretting state and reduce the wear of a substrate.

Previously, the wear resistances of steels after surface treatment, such as PN and LQ, have been successively studied. However, these researches mainly focused on the ball/pin on disk or reciprocating sliding wear mode [15, 22, 23], and the obtained data, such as the dynamic response and dissipated energy of the friction interface, are scarce. Moreover, comparative investigations of fretting wear behavior and damage mechanisms of various treatment surfaces based on engineering applications have rarely been reported.

In this study, AISI 4135 steel was treated by three economical and reliable surface modification techniques from two aspects of improving surface strength and reducing surface friction. Fretting wear tests were performed based on the actual service conditions. The wear behavior, dynamic response, energy dissipation, and damage mechanism of various treated surfaces were investigated. The results can provide theoretical support and application guidance for the design of surface modification of the locking mechanism.

\section{Materials and experimental procedures}

\subsection{Materials and surface treatment}

In this study, the commercial material AISI 4135 steel was used as the substrate, and its chemical composition were $0.35 \mathrm{wt} \%$ of $\mathrm{C}, 0.32 \mathrm{wt} \%$ of $\mathrm{Si}, 0.47 \mathrm{wt} \%$ of $\mathrm{Mn}, 0.87 \mathrm{wt} \%$ of $\mathrm{Cr}, 0.83 \mathrm{wt} \%$ of $\mathrm{Mo}$, and $\mathrm{Fe}$ balance. The main mechanical properties are listed in Table 1. After quenched-tempered heat treatment (heated to $850{ }^{\circ} \mathrm{C}$ for $30 \mathrm{~min}$, quenched in oil, and then tempered at $600{ }^{\circ} \mathrm{C}$ for $60 \mathrm{~min}$ ), the substrate was machined into samples with dimensions of $25 \mathrm{~mm} \times 12 \mathrm{~mm} \times 10 \mathrm{~mm}$ with a surface roughness of approximately $0.03 \mu \mathrm{m}$. Prior to surface treatment, the specimens were ultrasonically cleaned in acetone and dried in nitrogen. Subsequently, the prepared substrate specimens were separately treated by LQ, $\mathrm{PN}$, and bonded $\mathrm{MoS}_{2}$ coating. The process parameters of the three treatment methods are determined based on the properties of the locking pin material and the pre-test results.

A $\mathrm{CO}_{2}$ cross-flow laser was used to conduct LQ on the pretreated samples, and a hardening layer was formed on the surface. The laser power was $1.9 \mathrm{~kW}$, the dimensions of the laser beam were $10 \mathrm{~mm} \times 2 \mathrm{~mm}$ on the focal plane, and the scanning speed was $300 \mathrm{~mm} / \mathrm{min}$.

Additionally, PN treatment was performed using an LDM-200 PN furnace. First, the samples were placed in the furnace as a cathode, and the vacuum degree in the chamber was adjusted to reach $300-350 \mathrm{~Pa}$. The surfaces of the samples were cleaned for $20 \mathrm{~min}$ with hydrogen ion sputtering at $700 \mathrm{~V}$. Then, a mixture of $15 \% \mathrm{~N}_{2}$ and $85 \% \mathrm{H}_{2}$ was injected to maintain a pressure of $200 \mathrm{~Pa}$ in the chamber, and the nitriding

Table 1 Main mechanical properties of AISI 4135 steel and SiC ceramic ball.

\begin{tabular}{cccccc}
\hline Material & $\begin{array}{c}\text { Tensile strength } \\
(\mathrm{MPa})\end{array}$ & $\begin{array}{c}\text { Yield strength } \\
(\mathrm{MPa})\end{array}$ & $\begin{array}{c}\text { Young's modulus } \\
(\mathrm{GPa})\end{array}$ & $\begin{array}{c}\text { Hardness } \\
(\mathrm{HV})\end{array}$ & $\begin{array}{c}\text { Elongation } \\
(\%)\end{array}$ \\
\hline AISI 4135 & $\geq 985$ & $\geq 835$ & 206 & $240-269$ & $\geq 14$ \\
$\mathrm{SiC}$ & - & - & 400 & 1,650 & - \\
\hline
\end{tabular}


process was implemented at $530{ }^{\circ} \mathrm{C}$ for $15 \mathrm{~h}$. Finally, low-flow $\mathrm{H}_{2}$ was continued to be fed into the furnace until the temperature was below $100{ }^{\circ} \mathrm{C}$.

The preparation of the bonded $\mathrm{MoS}_{2}$ coating includes the following steps. $\mathrm{MoS}_{2}$ particles with a grain diameter of $0.5-1 \mu \mathrm{m}$ were uniformly dispersed in the adhesive (polyamide-imide and epoxy resin system) to form the mixture. The surfaces of the substrate samples were sanded in a random direction until rough $(\mathrm{Ra}=2 \pm 0.5 \mu \mathrm{m})$ and then coated with the mixture via spraying. Finally, the coating was solidified by heating to $150{ }^{\circ} \mathrm{C}$ for $30 \mathrm{~min}$ and then to $170{ }^{\circ} \mathrm{C}$ for $60 \mathrm{~min}$.

\subsection{Experimental method and parameters}

The fretting wear test was performed using a multifunctional fretting wear test system (MFTS-01) developed by Southwest Jiaotong University. A structural schematic and photograph of the test system are shown in Figs. 3(a) and 3(b), respectively. The reciprocating tangential motion is driven by a piezoelectric actuator, and the displacement control precision reached $\pm 0.2 \mu \mathrm{m}$ by the feedback of a grating encoder. Meanwhile, the force closed-loop control of the normal load $\left(F_{\mathrm{n}}\right)$ is realized by a servo loader and a load sensor, with a control accuracy of $\pm 0.3 \mathrm{~N}$. All signals are acquired by the multi-channel data acquisition unit, and then analyzed and processed by the host computer, consequently transmitted to the servo control unit to drive the actuators. Meanwhile, the tangential force $\left(F_{\mathrm{t}}\right)$ and actual displacement $(D)$ during the test were collected dynamically in real-time; hence, the typical $F_{\mathrm{t}}-D$ curves were automatically generated. As shown in Fig. 3(c), fretting wear tests were completed under the sphere-plane contact mode.

To simulate the wear state of the material under diverse vibration amplitudes, the fretting displacements (D) were controlled at 15,25 , and $50 \mu \mathrm{m}$. Based on the actual contact stress state of the locking pin and the experimental requirements, the normal load $(20 \mathrm{~N})$ is determined by the Hertz contact calculation, and the contact stress on the substrate is $841.1 \mathrm{MPa}$. In the present study, a high-stability $\mathrm{SiC}$ ceramic ball with a diameter of $10 \mathrm{~mm}$ was used as the counterpart, and its main parameters are listed in Table 1. The summarized test parameters are shown in Table 2, and each group of experiments was repeated three times.

\subsection{Characterization of treated surfaces and wear scars}

The phase structures of the specimens were analyzed using X-ray diffraction (XRD, D8 ADVANCE A25X, Bruker, Germany). A Vickers microhardness tester (MVK-H21, Akashi, Japan) was used to measure the hardness values of the sample surface and cross-section. Furthermore, the profile structures of the surfacetreated samples were observed using scanning electron microscopy (SEM, JSM-6610, JEOL, Japan) with an accelerating voltage of $20 \mathrm{kV}$.

After completion of the fretting wear tests, the morphologies of the fretting scars were measured using SEM and white light interferometry (Contour GT, Bruker, Germany). The chemical states of the elements on the worn surfaces were surveyed via X-ray photoelectron spectroscopy (XPS, ESCALAB $250 \mathrm{Xi}$, Thermo, USA) with an Al K $\alpha$ X-ray source.
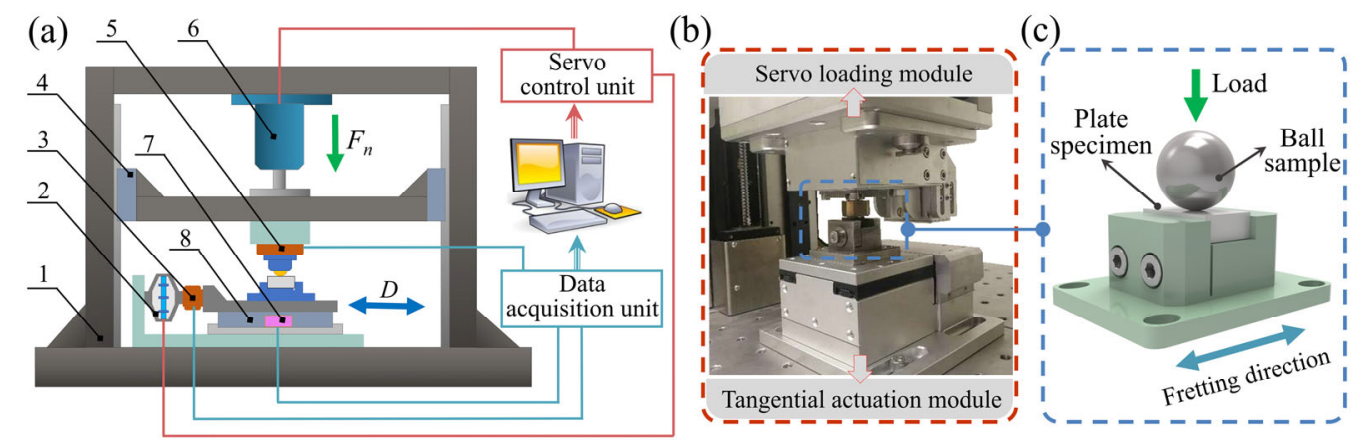

Fig. 3 (a) Structure of the fretting test system (1: gantry system, 2: piezoelectric actuator, 3: friction sensor, 4: linear guide, 5: load sensor, 6: servo loader, 7: grating displacement sensor, 8: linear guide); (b) photo of the test module; and (c) sphere-plane contact model. 
Table 2 Main test parameters in the study.

\begin{tabular}{cc}
\hline Test parameter & \\
\hline Displacement amplitude $(D, \mu \mathrm{m})$ & $15,25,50$ \\
Normal load $\left(F_{\mathrm{n}}, \mathrm{N}\right)$ & 20 \\
Frequency $(\mathrm{Hz})$ & 2 \\
Number of cycles $(N)$ & $1-5 \times 10^{3}$ \\
Temperature and humidity & $23 \pm 3{ }^{\circ} \mathrm{C}$ and $50 \% \pm 5 \%$ \\
Medium environment & Dry condition \\
\hline
\end{tabular}

The binding energy of the contaminated carbon (C 1s: $284.8 \mathrm{eV}$ ) as the benchmark and the peak value of the target element was calibrated with a resolution of approximately $\pm 0.3 \mathrm{eV}$.

\section{Results}

\subsection{Material characterization}

The three-dimensional morphologies of the sample surfaces are shown in Fig. 4(a). Compared with the substrate, the LQ sample has an equivalent surface roughness. However, due to plasma sputtering, the PN-treated surface was clearly rougher $(\mathrm{Ra}=0.64 \mu \mathrm{m})$ with a uniform texture. Similarly, the surface of the $\mathrm{MoS}_{2}$ coating had an irregular texture, and the maximum roughness reached $\mathrm{Ra}=1.05 \mu \mathrm{m}$.

XRD phase analysis was performed on the surfaces of the treated specimens, and the results are shown in Fig. 4(b). Sharp and strong diffraction peaks can be observed at $2 \theta$ angles of $44.46^{\circ}, 64.75^{\circ}$, and $82.11^{\circ}$ on the surfaces of the substrate and LQ samples, corresponding to the $\alpha$-Fe phase with high crystallinity. A compound layer of $\varepsilon-\mathrm{Fe}_{2-3} \mathrm{~N}$ and $\gamma^{\prime}-\mathrm{Fe}_{4} \mathrm{~N}$ was observed on the surface of the PN sample [32], but the peak reflection of $\alpha$-Fe was not observed. For the $\mathrm{MoS}_{2}$ coating, a remarkable peak (corresponding to the (002) lattice plane of $\mathrm{MoS}_{2}$ phase) appeared around $2 \theta=13^{\circ}$ in the XRD pattern. In addition, other characteristic peaks match well with the JCPDS data (JCPDS 37-1492), confirming the polycrystalline and hexagonal structure of the $\mathrm{MoS}_{2}$ particles [33].

As illustrated in Fig. 4(c), the surface and crosssectional microhardness test results were obtained. The hardness values of the surface and cross-section of the substrate remained stable between 250-300 HV. In contrast, those of the LQ and PN samples were significantly enhanced, reaching 565 and $552 \mathrm{HV}$, respectively. The hardness gradient was apparent on the cross-section of the LQ sample, and the depth of

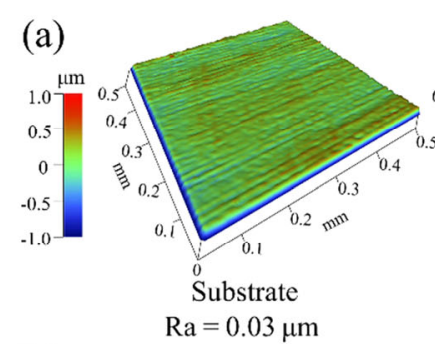

(b)

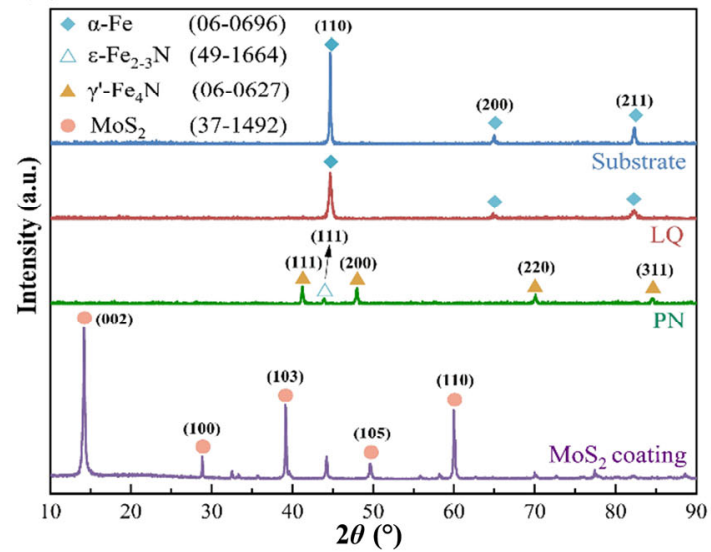

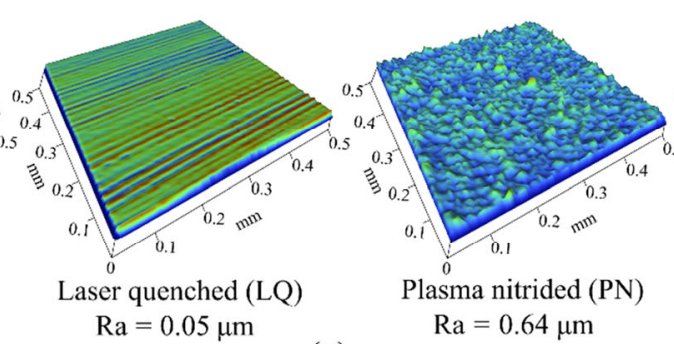

(c)

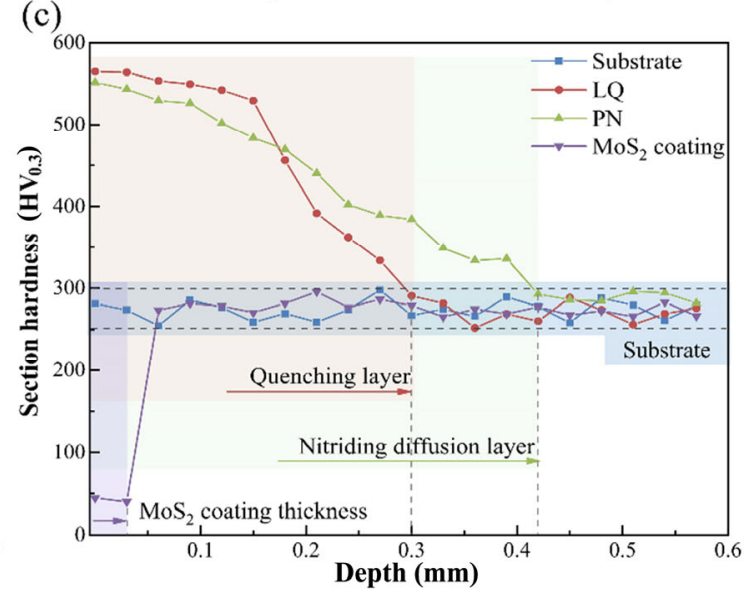

Fig. 4 (a) Three-dimensional morphologies of sample surfaces; (b) XRD patterns of samples; and (c) microhardness results of surface and profile of samples. 
the hardening layer reached approximately $0.3 \mathrm{~mm}$. However, the depth of diffusion layer for the PN sample was $0.42 \mathrm{~mm}$, and the hardness of the crosssection linearly decreased with the depth. In addition, owing to the interlaminar slippage of the $\mathrm{MoS}_{2}$ crystals, the surface layer $(\leq 0.03 \mathrm{~mm})$ hardness of the $\mathrm{MoS}_{2}$ coating was only approximately $48 \mathrm{HV}$.

The cross-sections of the samples were prepared (polished and then corroded with 3\% alcohol nitrate solution for $10 \mathrm{~s}$ ) and SEM images were obtained. Compared with the uniform phase structure of the substrate (Fig. 5(a)), the martensite structure [34] is generated after LQ treatment (Fig. 5(b)), which is an important factor for enhancing the hardness of the material. In addition, Fig. 5(c) shows that the surface of the PN sample was uniformly covered by micronsized spherical iron nitrite, while a dense compound layer of approximately $8 \mu \mathrm{m}$ was formed on the surface and diffused to the interior in a reticular manner. As shown in Fig. 5(d), the thickness of the bonded $\mathrm{MoS}_{2}$ coating was approximately $28 \mu \mathrm{m}$, and the randomly stacked micron-sized particles resulted in a rough surface.

\subsection{Dynamic response}

\subsection{1 $F_{t}-D-N$ curves}

The $F_{\mathrm{t}}-D-N$ curves with different tangential displacements are shown in Fig. 6, which reflect the fretting regimes of the contact interface. At $D=15 \mu \mathrm{m}$ in all test cycles, the $F_{\mathrm{t}}-D$ curves of the $\mathrm{MoS}_{2}$ coating are open, as parallelograms; specifically, fretting operated in the slip regime (SR). In contrast, the $F_{\mathrm{t}}-D$ curves of the substrate and the other surface-treated samples changed rapidly from parallelogram to linear with the increase in test cycles. This indicates that the contaminated film (oxide film, adsorption film) on the contact interface was removed in the initial test cycles, the imposed displacement was mainly absorbed by the elastic deformation of the contact material, and the fretting wear operated in the partial slip regime (PSR) [4]. For $D=25$ and $50 \mu \mathrm{m}$, the $F_{\mathrm{t}}-D$ curves of the substrate and the three treated samples were all quasi-rectangular. It is clear that the imposed displacement was mainly dominated by the plastic deformation of the contact surface; thus, fretting was operated in the SR.

\subsubsection{Energy dissipation}

Referring to Fig. 7(a), trapezoidal integration was performed on the single-cycle $F_{\mathrm{t}}-D$ curve (Eq. (1)), and the energy dissipation of a single cycle $\left(E_{\mathrm{s}}\right)$ was obtained. Furthermore, the accumulated energy dissipation $\left(E_{\mathrm{d}}\right)$ of the entire wear process was acquired via Eq. (2),

$$
E_{\mathrm{s}}=2\left(\int_{-\delta 0}^{\delta m} f \mathrm{~d} \delta-\int_{\delta 0}^{\delta m} f \mathrm{~d} \delta\right)
$$
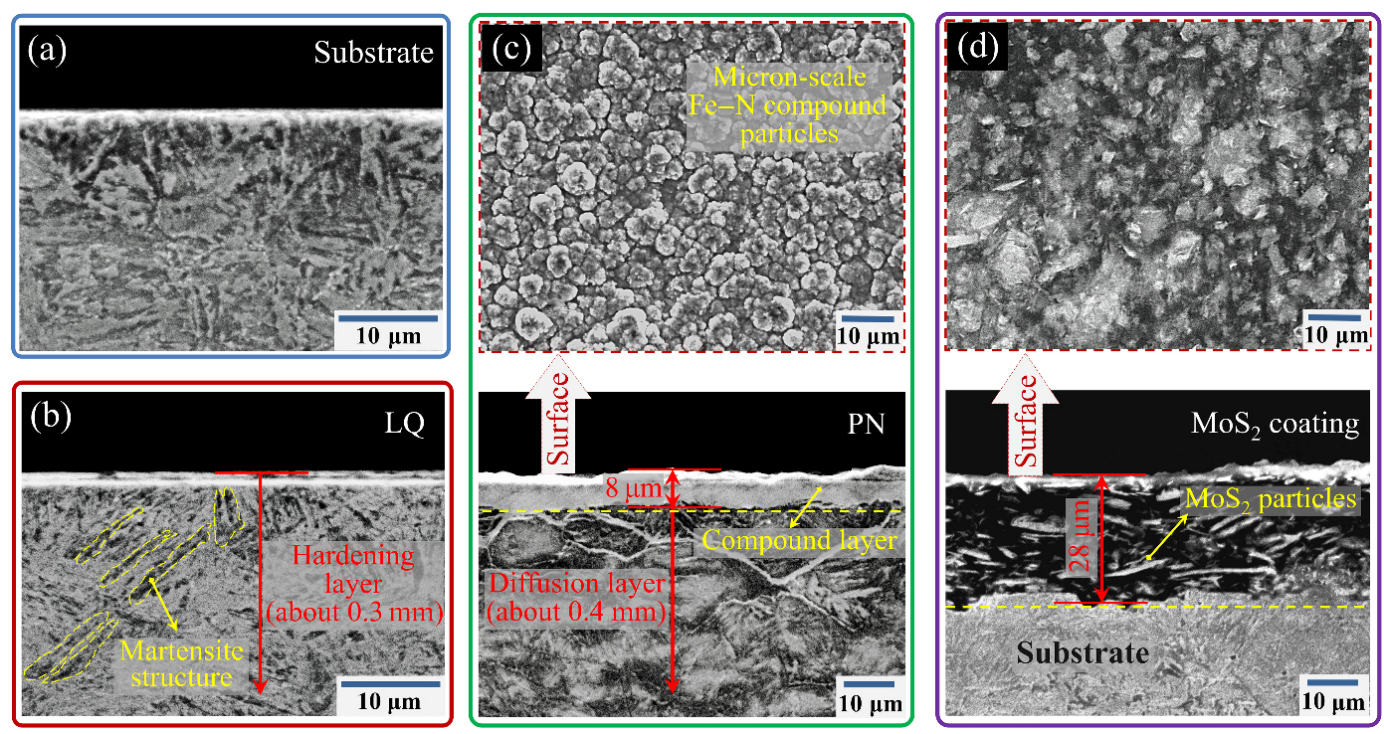

Fig. 5 Surface and cross-sectional SEM images of (a) substrate; (b) LQ; (c) PN; and (d) bonded $\mathrm{MoS}_{2}$ coating. 


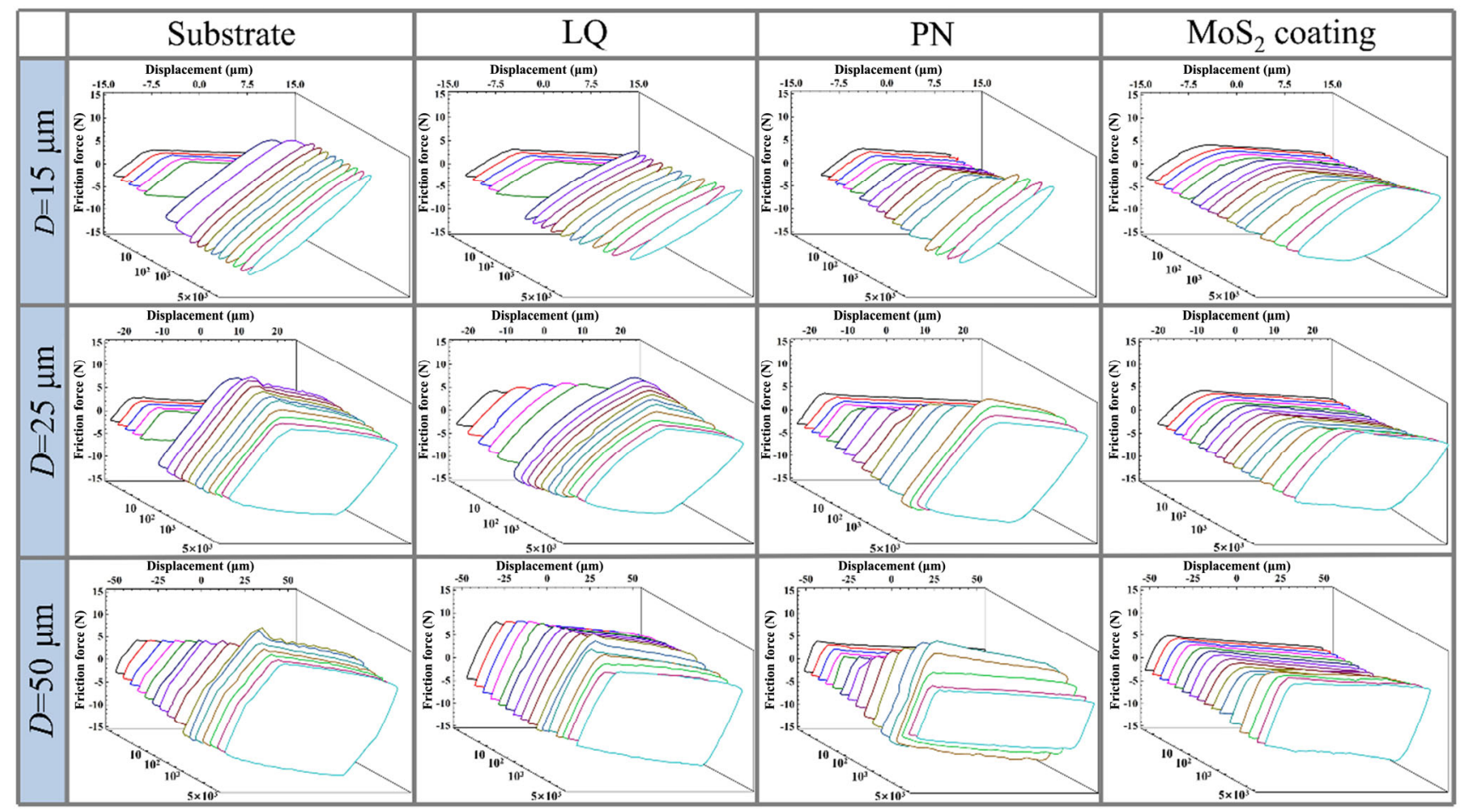

Fig. $6 \quad F_{\mathrm{t}}-D-N$ curves of different samples under various fretting displacements.

(a)

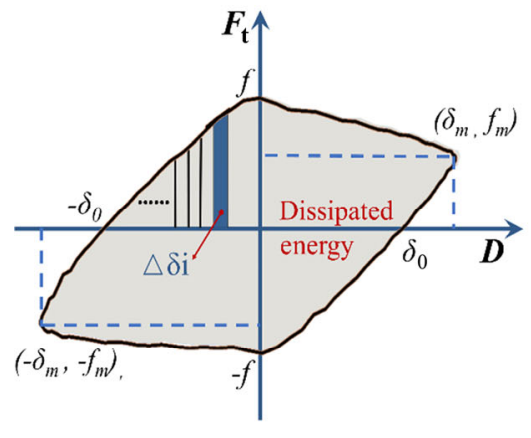

(b)

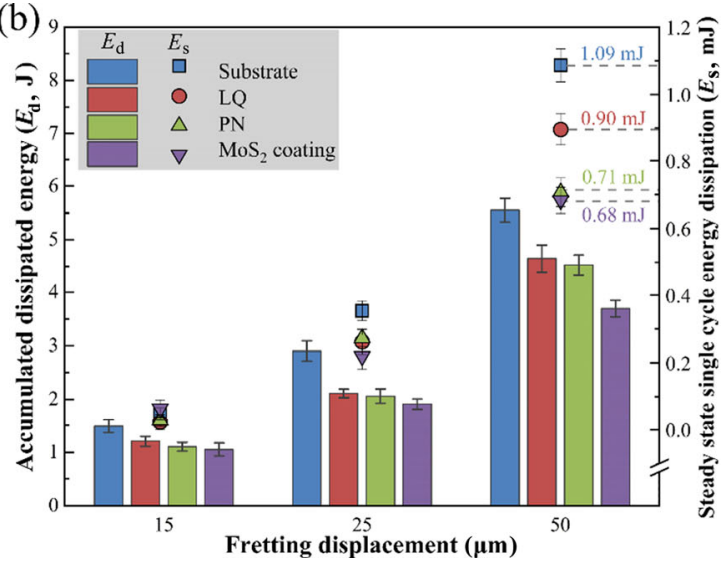

Fig. 7 (a) Calculation method of energy dissipation and (b) cumulative and single-cycle energy dissipation of different samples.

$$
E_{\mathrm{d}}=\sum_{s=1}^{5,000} E_{\mathrm{s}}
$$

As shown in Fig. 7(b), $E_{\mathrm{d}}$ of the surface-treated samples increased significantly with an expansion of the displacement. Compared with the substrate, in different fretting regimes, $E_{\mathrm{d}}$ of the three surfacetreated specimens decreased to different degrees. The self-lubricating properties of the $\mathrm{MoS}_{2}$ coating resulted in the minimum $E_{\mathrm{d}}$, especially at $D=50 \mu \mathrm{m}$, which was approximately $67 \%$ of that of the substrate. In addition, $E_{\mathrm{s}}$ in the steady state was positively correlated with the increasing trend of fretting displacement, and the dissipated energy of the substrate and surfacetreated samples followed the descending order of substrate, LQ, PN, and $\mathrm{MoS}_{2}$ coating.

\subsection{Coefficient of friction (COF)}

The COF is the ratio between the friction force $\left(F_{\mathrm{t}}\right)$ and normal load $\left(F_{n}\right)$, which plays an essential role in evaluating fretting wear behavior. Figures $8(a)-8(c)$ show the evolutions of the COFs for various treated 
samples with different displacements. For $D=15 \mu \mathrm{m}$ (Fig. 8(a)), the COF varied with the test cycles and comprised three stages: initial; ascending; and steady. In the initial stage (before the 10th cycle), owing to the presence of the contaminated film, the fretting interface had a low COF (approximately 0.2). After different periods of the ascending stage, the COF of each sample reached a stable value, and followed the descending order of substrate, LQ, PN, and $\mathrm{MoS}_{2}$ coating. The COF of the PN sample was stable after running-in for 1,600 cycles because of its texture and high hardness. In contrast, the COF of the $\mathrm{MoS}_{2}$ coating increased slowly from 0.18 to approximately 0.38 , showing an excellent fretting wear resistance.

As the fretting displacement increased to 25 and $50 \mu \mathrm{m}$, a complex evolution of the COF appeared in the SR, as shown in Figs. 8(b) and 8(c). The initial stages of the substrate and LQ sample were significantly shortened, and the COF decreased and fluctuated after reaching the maximum value until the steady state was reached around 3,000 cycles. This occurred because the increased friction led to the aggravation of wear, and fretting debris was constantly produced and gradually carried the normal load, which promoted the decrease in the COF. Moreover, when the formation and discharge of the third bodies reached a dynamic equilibrium, the COF was in a steady state. At the initial stage of $D=50 \mu \mathrm{m}$, the contaminated film (oxide film and adsorption film) that exist in the contact interface was rapidly destroyed due to the high-hardness LQ treated surface, the adhesion and plastic deformation of the mating materials occurred. Therefore, the COF of the LQ sample increased rapidly and is slightly higher than that of the substrate. The COF of the PN sample maintained a long period of the low-friction ascending stage (approximately $800-900$ cycles) under the displacements of 25 and $50 \mu \mathrm{m}$, which was inseparable from the rough surface of the nitriding layer. The roughness peak of the PN sample surface carried the normal load and had a higher Hertz contact stress than those of the other specimens. Then, the plastic deformation and adhesion of the friction pair induced the decrease of relative slip, and fretting wear tended to PSR; therefore, it had a smaller COF. In addition, compared with the other samples, the interlaminar slip characteristic of $\mathrm{MoS}_{2}$
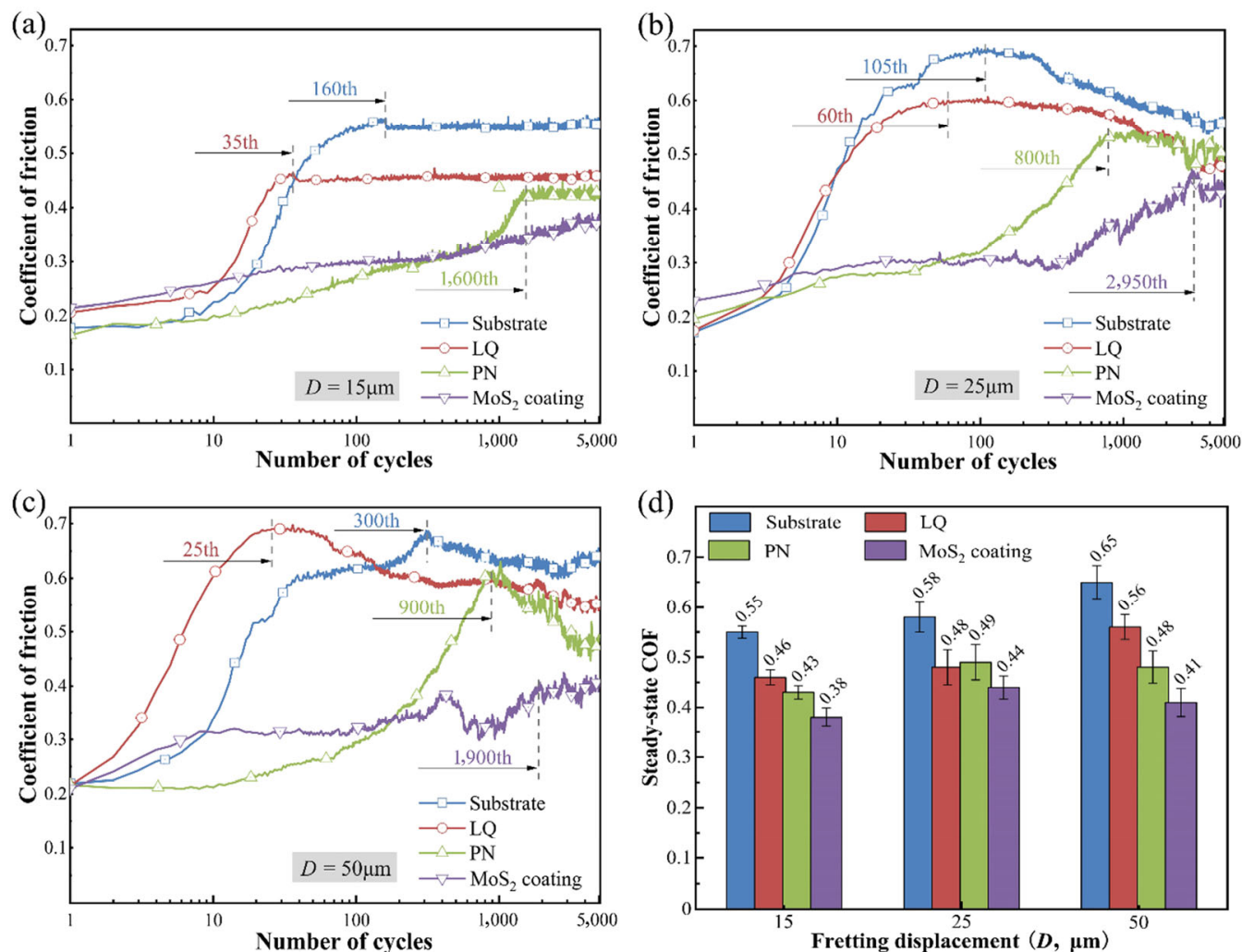

Fig. 8 Analysis of the COF for (a) $D=15 \mu \mathrm{m}$, (b) $D=25 \mu \mathrm{m}$, and (c) $D=50 \mu \mathrm{m}$; and (d) comparisons of the steady-state COF. 
crystals contributed to the lower COF under different fretting displacements [35]. However, due to the accumulation of the work hardening and microdefects upon fretting wear, the self-lubricating effect of the coating gradually weakened, consequently leading to the increase of COF with cycles.

In order to deeply analyze the mechanical response of various treated surfaces on fretting wear, the steadystate COFs determined by averaging COF from the steady stage of friction coefficient curves were obtained, as shown in Fig. 8(d). For the $\mathrm{MoS}_{2}$ coating with excellent self-lubricating properties, the lowest COF was observed. In addition, although the surface hardness of the PN sample was slightly lower than that of the LQ sample, the lower steady-state COF demonstrated that the texture on the PN-treated surface played a pivotal role in reducing friction. Therefore, in terms of the antifriction effect, the treated surfaces were superior to the substrate, and the $\mathrm{MoS}_{2}$ coating was the best, followed by the PN sample.

\subsection{Wear analysis}

\subsubsection{Damage observations}

The wear morphologies of the substrate and various surface-treated samples in the PSR $(D=15 \mu \mathrm{m})$ were obtained, as shown in Fig. 9. As illustrated in Figs. 9(a) and $9(\mathrm{~b})$, typical fretting rings appeared on the surfaces of the substrate and LQ sample. Compared with the substrate, the LQ sample had a smaller scar area, a narrower slip band (approximately $35 \mu \mathrm{m}$ ), and no obvious heart damage due to its higher surface hardness. In Fig. 9(c), the rough texture of the PN sample resulted in an irregular fretting scar, uneven contact area, and slight furrows. In addition, as shown in Fig. 9(d), severe plastic deformation and layered stacking occurred at the contact interface of the $\mathrm{MoS}_{2}$ coating, and flaky peeling appeared.

For the SR of fretting $(D=50 \mu \mathrm{m})$, the threedimensional and microscopic wear morphologies of different samples are shown in Fig. 10. As shown in Fig. 10(a), the LQ and PN samples with enhanced surface hardness exhibited less abrasion than the substrate. In contrast, a deep pit formed on the $\mathrm{MoS}_{2}$ coating owing to its severe plastic deformation. In Figs. 10(b) and 10(c), obvious furrows and delamination existed on the surfaces of the substrate and LQ sample, accompanied by a mass of wear debris. In contrast, the contact area of the PN sample was slightly damaged, with shallow furrows in the heart and delamination at the edge of the scar (Fig. 10(d)). However, owing to plastic flow and surface work hardening in the

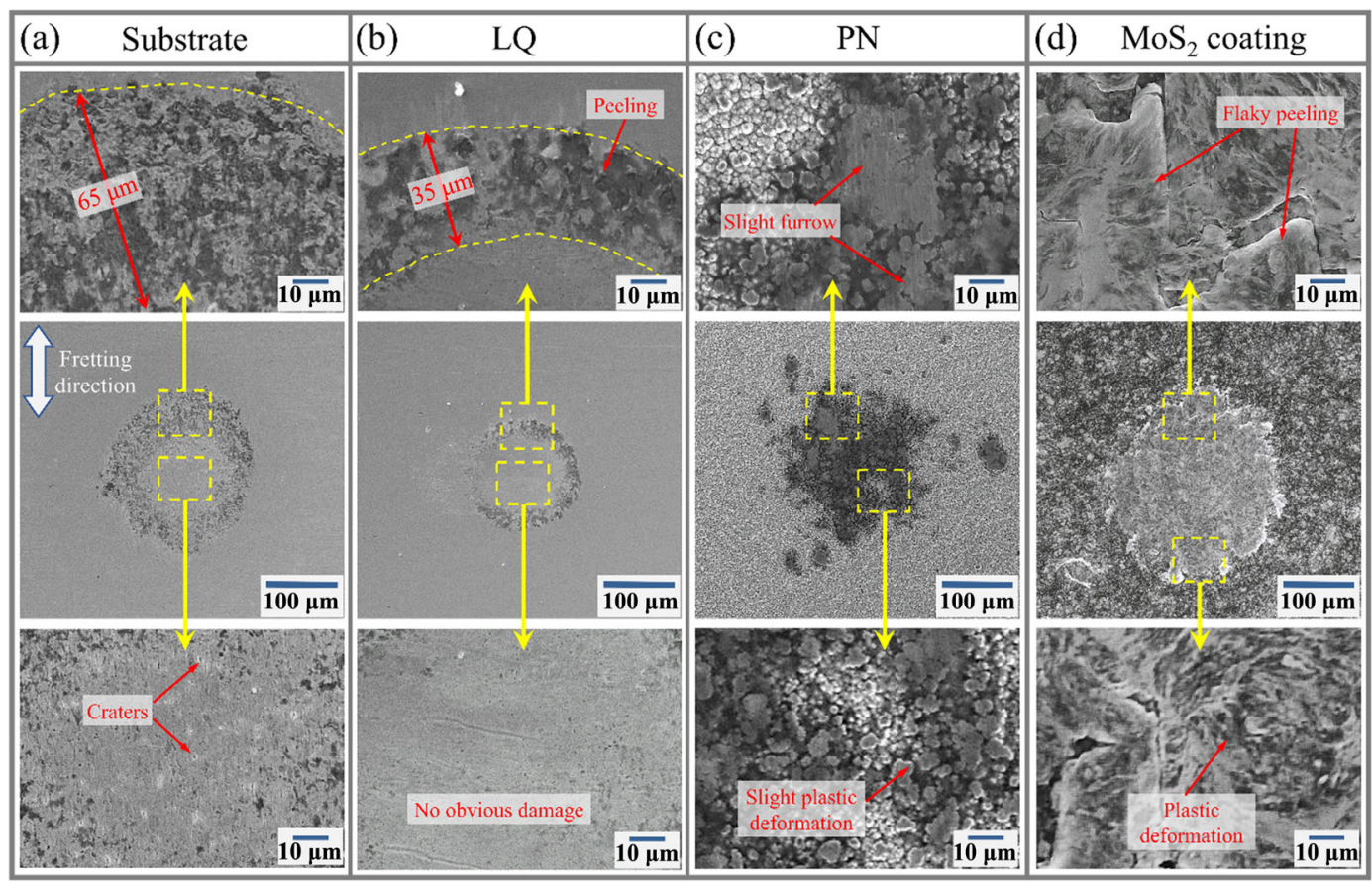

Fig. 9 Wear morphologies of different treated surfaces in fretting PSR. 


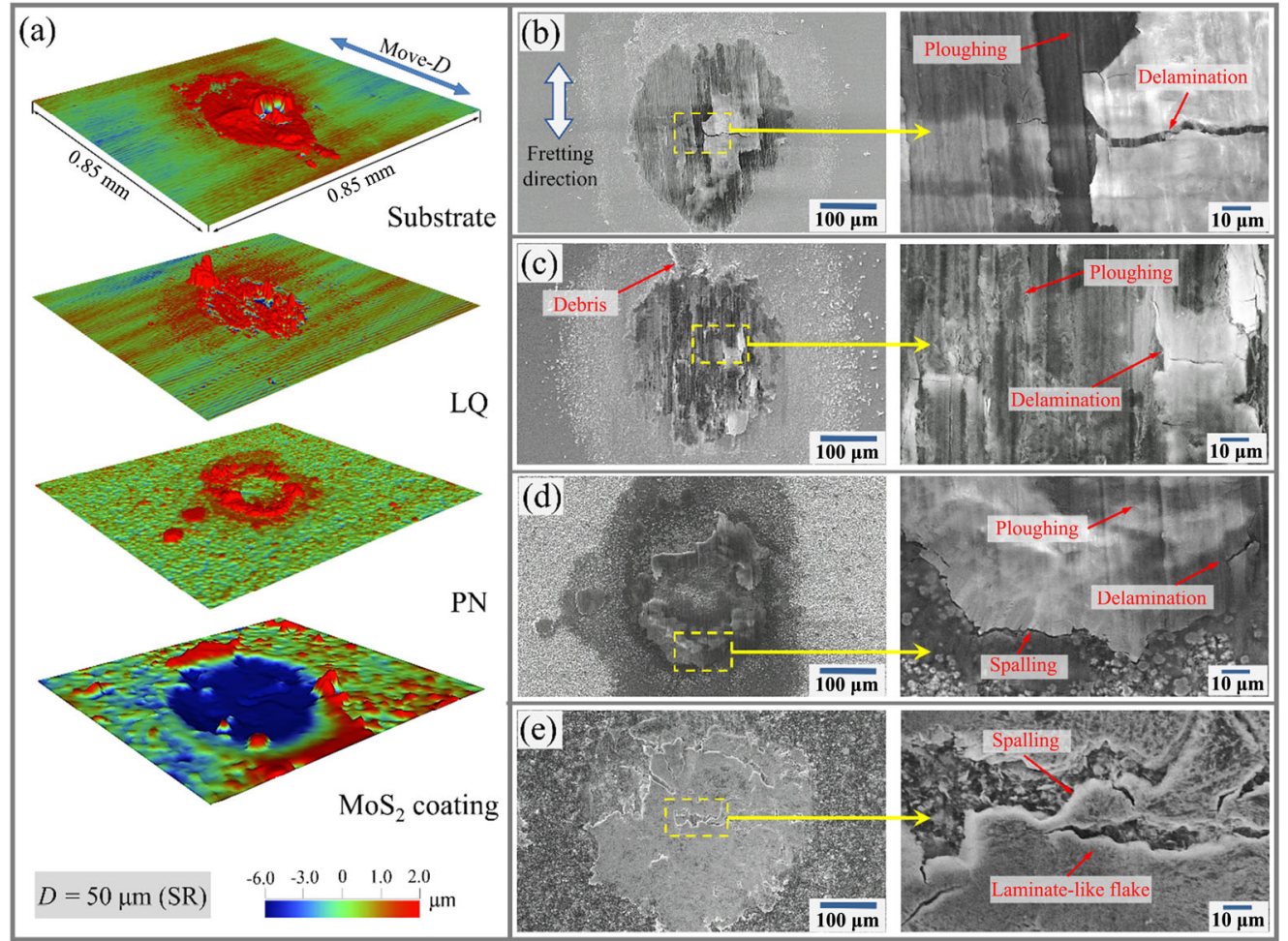

Fig. 10 Wear morphologies of different treated surfaces in fretting SR. (a) Three-dimensional morphologies; (b) substrate; (c) LQ; (d) PN; and (e) bonded $\mathrm{MoS}_{2}$ coatings.

contact area of the $\mathrm{MoS}_{2}$ coating, cracks and flaking occurred, and the internal $\mathrm{MoS}_{2}$ particles were exposed (Fig. 10(e)).

\subsubsection{Abrasion loss}

The variation in the wear scar depth of different samples is shown in Fig. 11(a). With an increase in fretting displacement, the depth and width of the fretting scar gradually expanded. The wear depths of the LQ and PN samples were the lowest in various fretting regimes, followed by the substrate. Furthermore, the wear depth positively correlates with the surface hardness of the samples.

As shown in Fig. 11(b), the wear volumes and areas of the four samples under different fretting displacements were comprehensively compared. In different fretting regimes, the PN sample had the lowest wear volume, followed by the LQ sample, and then the substrate. In particular, at the displacement of $50 \mu \mathrm{m}$, the volume loss of the PN sample was
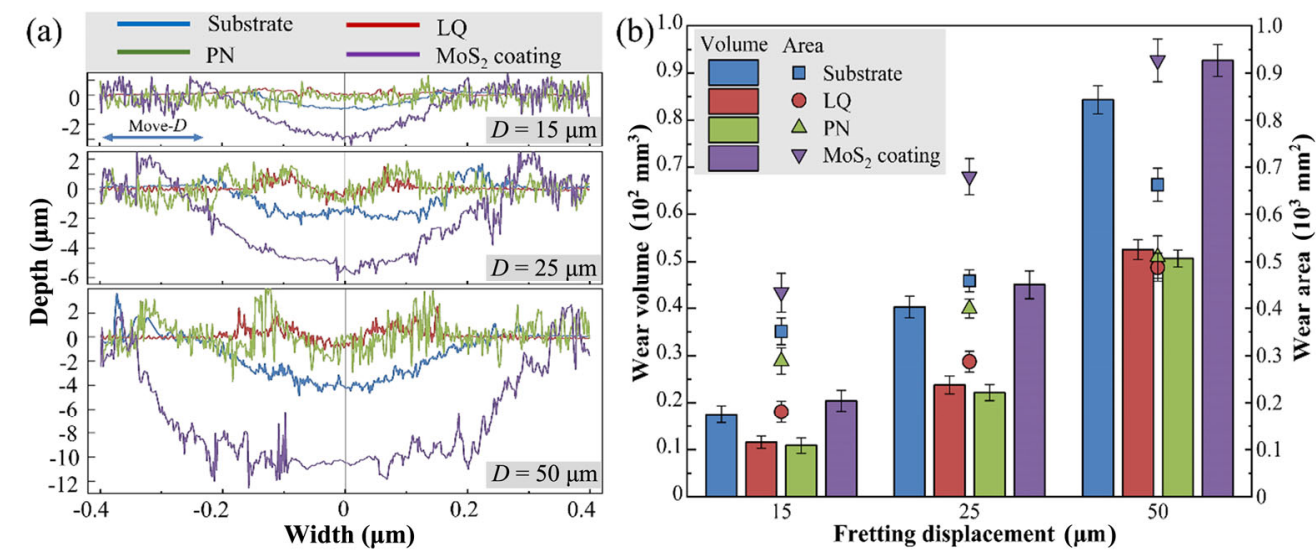

Fig. 11 (a) Cross-sectional profiles of fretting wear scars and (b) comparison of wear volumes and wear areas. 
reduced by $41 \%$ compared with that of the substrate. Similarly, the comparison results of the scar area are consistent with the results of wear volume. However, it is noteworthy that the wear area of the PN sample was slightly larger than that of the LQ sample, due to the surface texture. For the $\mathrm{MoS}_{2}$ coating, owing to its low surface hardness and inter-crystal slip characteristics, the wear volume and area were the largest under the same experimental conditions.

\subsection{Tribochemical analysis}

In the SR $(D=50 \mu \mathrm{m})$, the tribochemical states on worn scars of different treated surfaces were characterized. The binding energies of all elements obtained by XPS were calibrated, and the convolution was performed using a Shirley background.

Figures 12(a)-12(c) show the Fe 2p high-resolution spectral analyses of the substrate, LQ, and PN samples, respectively. Considering the substrate (Fig. 12(a)), there were two Fe $2 \mathrm{p}_{3 / 2}$ binding energy peaks at 710.62 and $712.3 \mathrm{eV}$, and two Fe $2 \mathrm{p}_{1 / 2}$ binding energy peaks at 723.7 and $725.9 \mathrm{eV}$, respectively [36]. Among them, the two peaks at 710.62 and $723.7 \mathrm{eV}$ may be attributed to the binding energy of $\mathrm{Fe}-\mathrm{O}$ in $\mathrm{FeO}\left(\mathrm{Fe}^{2+}\right)$, while those at 712.3 and $725.9 \mathrm{eV}$ are assigned to $\mathrm{Fe}^{3+}$ in $\mathrm{Fe}_{2} \mathrm{O}_{3}$. In addition, two peaks at 706.75 and $719.9 \mathrm{eV}$ were found in the Fe $2 \mathrm{p}$ high-resolution spectrum of the LQ sample (Fig. 12(b)), indicating the presence of $\mathrm{Fe}^{0}$ after abrasion.

Integral statistics were performed for the percentage of peak area in the Fe $2 p$ high-resolution spectrum, and the results are shown in Table 3. Previous studies have indicated that $\mathrm{Fe}$ atoms on the surface of the sample form an oxidation film (mainly $\mathrm{FeO}$ ) in the air, and the oxidation reaction is activated by friction to promote the transformation of $\mathrm{FeO}$ into $\mathrm{Fe}_{2} \mathrm{O}_{3}[36,37]$. Therefore, the three samples were oxidized to varying degrees in fretting wear, of which the content of $\mathrm{Fe}^{3+}$

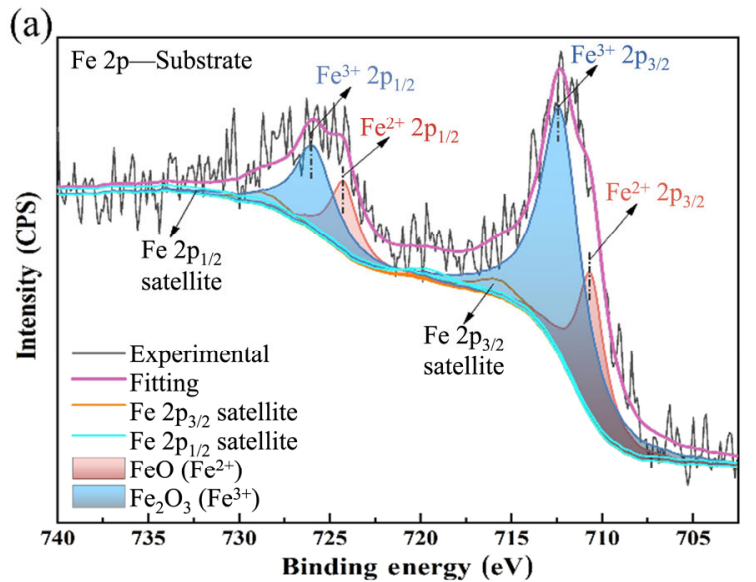

(b)
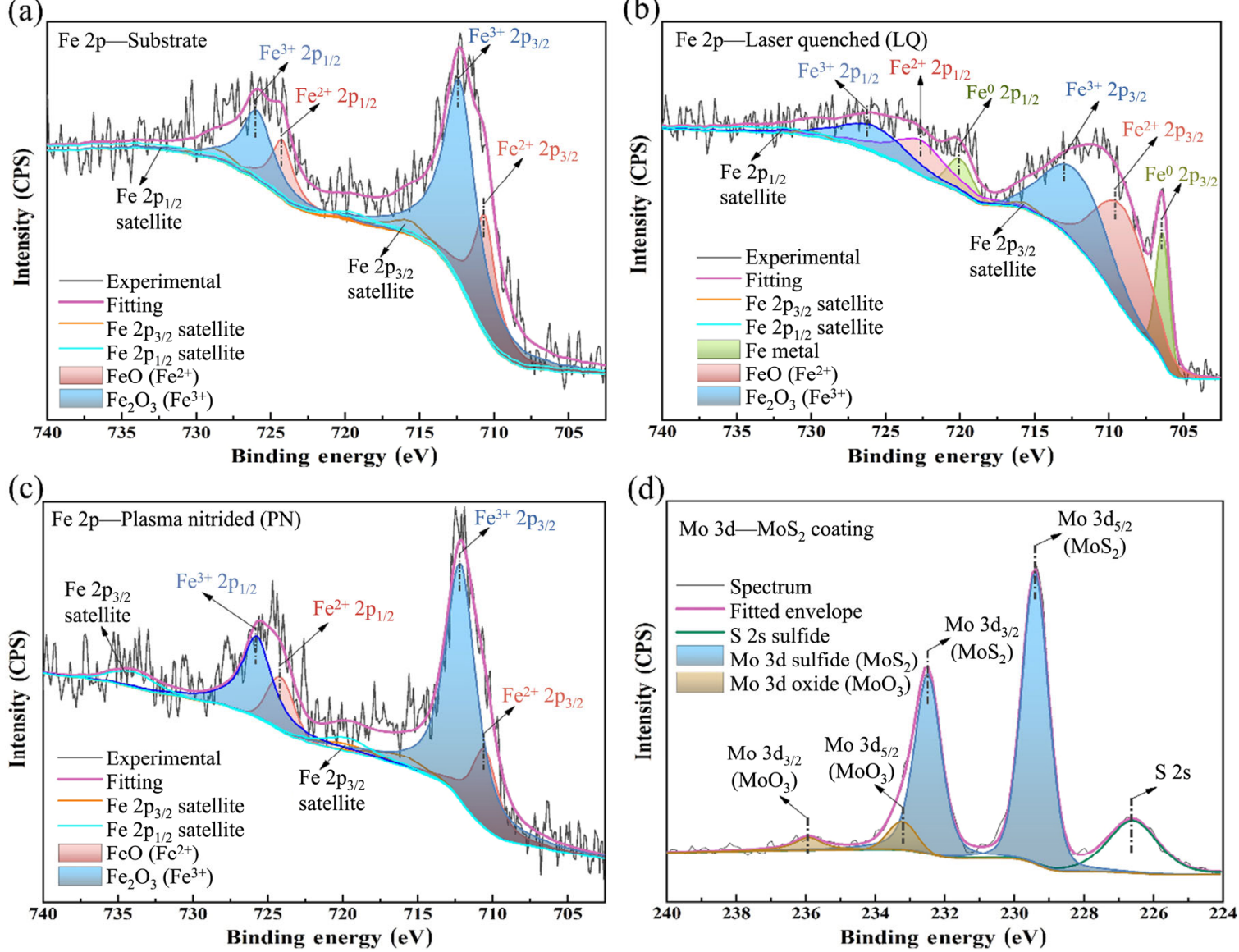

Fig. 12 High-resolution Fe 2p spectra for the scar of (a) substrate, (b) LQ sample, and (c) PN sample; and (d) high-resolution Mo 3d spectra for the scar of bonded $\mathrm{MoS}_{2}$ coating. 
Table 3 Peak positions of Fe $2 p$ XPS results and corresponding area ratios of different fretting interfaces.

\begin{tabular}{|c|c|c|c|c|c|c|c|c|c|}
\hline \multirow{3}{*}{ Sample } & \multicolumn{6}{|c|}{ Peak position $( \pm 0.3 \mathrm{eV})$} & \multicolumn{3}{|c|}{ Area ratio $(\%)$} \\
\hline & \multicolumn{2}{|c|}{$\mathrm{Fe}$ metal $\left(\mathrm{Fe}^{0}\right)$} & \multicolumn{2}{|c|}{$\mathrm{FeO}\left(\mathrm{Fe}^{2+}\right)$} & \multicolumn{2}{|c|}{$\mathrm{Fe}_{2} \mathrm{O}_{3}\left(\mathrm{Fe}^{3+}\right)$} & \multirow{2}{*}{$\begin{array}{c}\mathrm{Fe} \\
\left(\mathrm{Fe}^{0}\right)\end{array}$} & \multirow{2}{*}{$\begin{array}{c}\mathrm{FeO} \\
\left(\mathrm{Fe}^{2+}\right)\end{array}$} & \multirow{2}{*}{$\begin{array}{l}\mathrm{Fe}_{2} \mathrm{O} \\
\left(\mathrm{Fe}^{3+}\right)\end{array}$} \\
\hline & $\mathrm{Fe}^{0} 2 \mathrm{p}_{3 / 2}$ & $\mathrm{Fe}^{0} 2 \mathrm{p}_{1 / 2}$ & $\mathrm{Fe}^{2+} 2 \mathrm{p}_{3 / 2}$ & $\mathrm{Fe}^{2+} 2 \mathrm{p}_{1 / 2}$ & $\mathrm{Fe}^{3+} 2 \mathrm{p}_{3 / 2}$ & $\mathrm{Fe}^{3+} 2 \mathrm{p}_{1 / 2}$ & & & \\
\hline Substrate & - & - & 710.62 & 723.72 & 712.3 & 725.9 & 0 & 24.06 & 75.94 \\
\hline LQ & 706.75 & 719.9 & 709.02 & 722.62 & 712.18 & 725.78 & 13.24 & 31.14 & 55.62 \\
\hline PN & - & - & 710.54 & 723.14 & 712.13 & 725.73 & 0 & 30.77 & 69.23 \\
\hline
\end{tabular}

in the scar of the substrate was the highest, reaching $75.94 \%$. In contrast, the $\mathrm{Fe}^{3+}$ contents in the wear products of the LQ and PN samples were reduced to $55.62 \%$ and $69.23 \%$, respectively. The fact that Fe metal was present in the worn scar of the LQ sample may be owing to the possibility that fresh matrix exposed to the scar surface due to material spalling has not been completely oxidized.

Figure 12(d) illustrates the Mo 3d high-resolution spectra of the scar on the $\mathrm{MoS}_{2}$ coating. Evidently, the binding energy peaks of $\mathrm{MoS}_{2}$ appeared at 229.4 and $232.5 \mathrm{eV}$, while those of $\mathrm{MoO}_{3}$ were located at 233.0 and $235.8 \mathrm{eV}[38,39]$. The formation of $\mathrm{MoO}_{3}$ was caused by the oxidation reaction of $\mathrm{Mo}^{4+}$ to $\mathrm{Mo}^{6+}$ during the wear process [40].

\section{Discussion}

Based on the structural features and service conditions of the locking pin, combined with the dynamic response on the fretting wear, it is determined that the fretting damage of the mechanical component is mainly located in the SR. Therefore, the damage mechanism and anti-wear properties of various treated surfaces for the fretting displacement of $50 \mu \mathrm{m}$ are discussed comprehensively herein, and an optimal surface treatment method suitable for this component is recommended.

\subsection{Wear mechanism of various treated surfaces}

Combined with the damage morphologies (Fig. 10) and tribochemical states (Fig. 12), the wear mechanism of different samples is summarized. Various degrees of furrows and delamination, as well as oxidation products, were detected in the abrasion scars of the substrate and the two wear-resistant surfaces (LQ- and PN-treated surfaces). This indicates that their wear mechanism was mainly due to the combination of abrasive wear, delamination, and oxidation wear. In addition, work hardening and flaky peeling were apparent in the scar of the $\mathrm{MoS}_{2}$ coating, and its wear mechanism was plastic deformation and peeling, accompanied by oxidative wear.

\subsection{Evaluation of anti-fretting damage performance}

Based on the functional relationship between dissipated energy (Fig. 7(b)) and wear volume (Fig. 11(b)), as shown in Fig. 13(a), the energy-based wear rate was obtained [41]. Previous studies have confirmed that wear amount is inversely proportional to the hardness of a material [42]. In the case of a small fretting displacement, severe strain hardening occurred on the contact surface; therefore, a lower wear rate was observed in the PSR $(D=15 \mu \mathrm{m})$. Compared with the substrate and antifriction coating, the two wearresistant surfaces with high hardness contributed to their lower wear rates. Moreover, the PN sample exhibited the best wear resistance owing to the wear reduction effect of the surface texture.

From Fig. 13(b), the PN-treated surface displayed the best comprehensive performance in the SR of fretting, followed by the LQ-treated surface. In contrast, the martensite structure with high hardness for LQtreated surface lower the plastic flow capability of the material, which will make cracks being prone to be initiated and propagated [43]. Although the selflubricating properties of the $\mathrm{MoS}_{2}$ coating contributed to the lowest COF and dissipated energy, the low stiffness will inevitably expand the fit clearance of the locking mechanism, which may aggravate the impact and vibration of the components in actual working conditions. In summary, PN is the preferred surface treatment method for locking pin materials. 

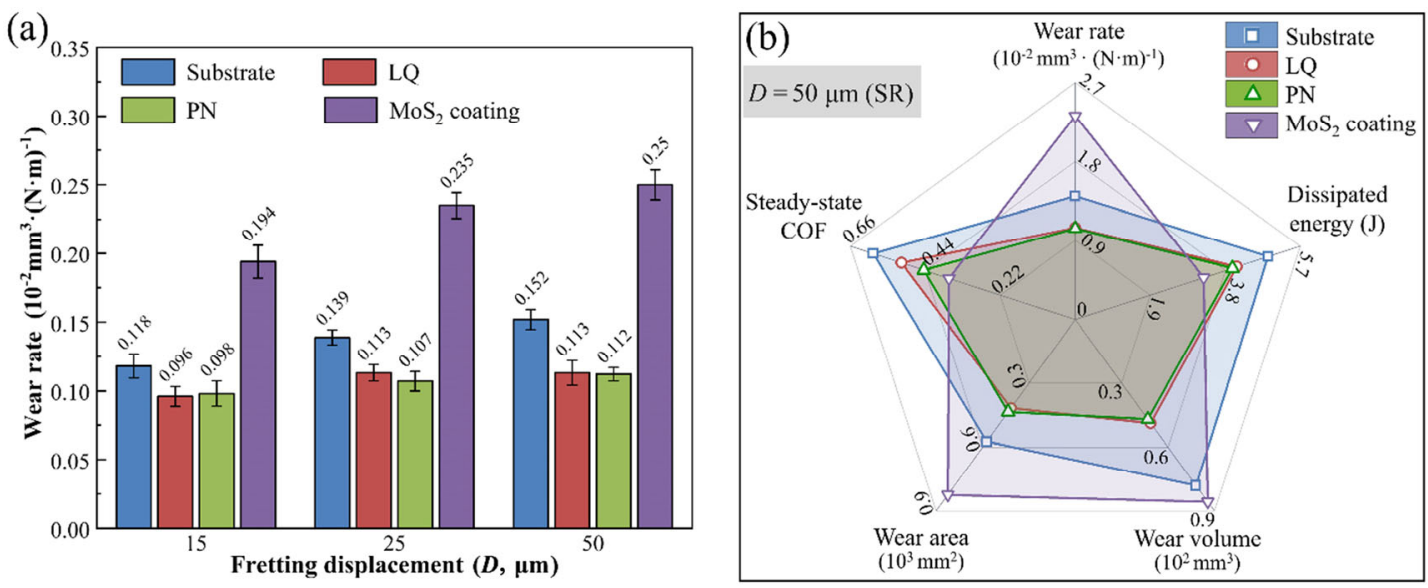

Fig. 13 Comparisons of the (a) energy-based wear rate and (b) comprehensive wear resistances.

\subsection{Alleviating fretting damage mechanism of the PN-treated surface}

To demonstrate the reason why the PN-treated surface alleviated the fretting damage, an idealized model was established, as shown in Fig. 14. As mentioned above (Section 3.1), the PN-treated surface is covered with high-hardness spherical ferro-nitride $\left(\mathrm{Fe}_{2-3} \mathrm{~N}\right.$ and $\mathrm{Fe}_{4} \mathrm{~N}$ ), which increases the roughness while strengthening the surface. The surface texture results in higher contact stress, and the material adhesion at the contact interface increased. Furthermore, part of the imposed displacement was coordinated by the elastic deformation of the material, which reduced the damage. Meanwhile, as the third bodies (Fig. 14(a)), the ferro-nitride particles exfoliated quickly and were collected by the texture, which plays the role of bearing and lubrication. Referring to the wear morphologies in Fig. 14(c), ring-shaped lamellae were formed on the edge of the scar by stacking and rolling (Fig. 14(b)), which retarded the discharge of debris from the contact area, thereby consolidating the wearreducing effect of the third bodies (Fig. 14(d)).

In addition, the coarse porous compound layer provided a favorable environment for the storage and release of lubrication medium. The PN-treated surface may exhibit better anti-fretting effects under lubrication conditions, which needs to be further explored in the follow-up studies.

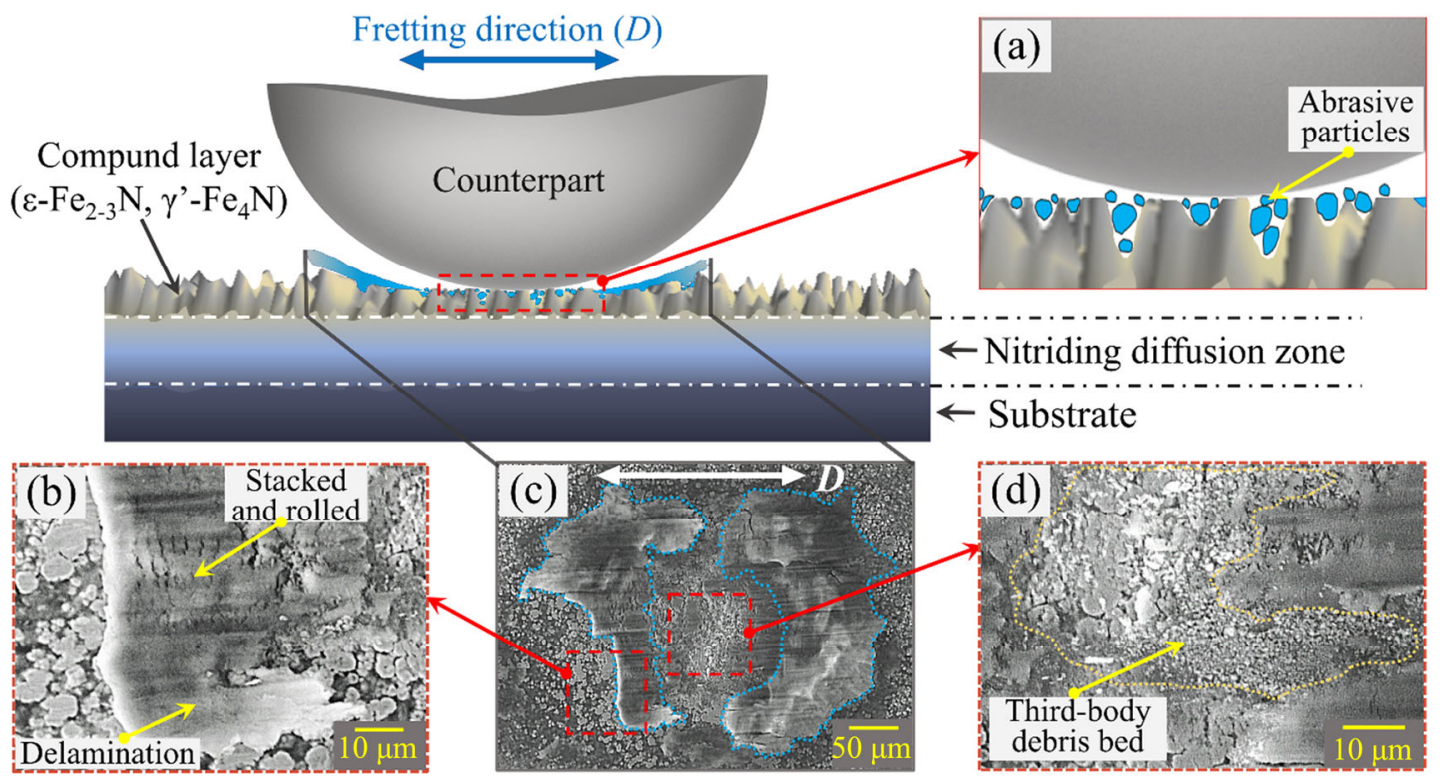

Fig. 14 Mechanism of reducing fretting wear on PN-treated surface. 


\section{Conclusions}

Three surface treatments were applied to the locking pin material (AISI 4135 steel), the fretting wear experiments and various characterization analyses were performed. The wear behavior and damage mechanisms of the various treated surfaces were investigated. Several conclusions can be drawn from the results and discussion.

1) The surface hardness of laser quenching (LQ) and plasma nitriding (PN) samples was enhanced, and a lower fretting wear rate was obtained. The main wear mechanisms of the two strengthened surfaces were abrasive wear, delamination, and oxidation wear, while the damage of PN surface is slight.

2) The $\mathrm{MoS}_{2}$ coating had the lowest coefficient of friction (COF) and dissipation energy in different fretting regimes, but the highest wear rate. The main types of failure were plastic deformation, delamination, and oxidative wear.

3) $\mathrm{PN}$ is preferred as a surface-strengthening measure for locking pin materials. The rough compound layer causes fretting to tend to the partial slip state, forming and maintaining a third-body bed that mitigates wear.

4) This research provides a reference for the surface protection of related mechanical structures in the engineering field to alleviate fretting damage.

\section{Acknowledgements}

This work was supported by the National Natural Science Foundation of China (Grant No. 51627806).

Open Access This article is licensed under a Creative Commons Attribution 4.0 International License, which permits use, sharing, adaptation, distribution and reproduction in any medium or format, as long as you give appropriate credit to the original author(s) and the source, provide a link to the Creative Commons licence, and indicate if changes were made.

The images or other third party material in this article are included in the article's Creative Commons licence, unless indicated otherwise in a credit line to the material. If material is not included in the article's Creative Commons licence and your intended use is not permitted by statutory regulation or exceeds the permitted use, you will need to obtain permission directly from the copyright holder.

To view a copy of this licence, visit http://creativecommons.org/licenses/by/4.0/.

\section{References}

[1] He H. Key challenges and countermeasures with railway accessibility along the silk road. Engineering 2(3): 288-291 (2016)

[2] Szkoda M, Michnej M. A method of fretting wear reduction in an automatic wheel set gauge change system. Eng Fail Anal 45: 363-375 (2014)

[3] Huq M Z, Butaye C, Celis J P. An innovative system for fretting wear testing under oscillating normal force. J Mater Res 15(7): 1591-1599 (2000)

[4] Zhu M H, Zhou Z R. On the mechanisms of various fretting wear modes. Tribol Int 44(11): 1378-1388 (2011)

[5] Rai P K, Shekhar S, Mondal K. Effects of grain size gradients on the fretting wear of a specially-processed low carbon steel against AISI E52100 bearing steel. Wear 412-413: 1-13 (2018)

[6] BS EN 13104-2009 Railway applications-wheelsets and bogies-powered axles-design method. BSI, 2009.

[7] BS EN 13979-1 Railway applications-wheelsets and bogiesmonobloc wheels-technical approval procedure-Part 1: Forged and rolled wheels. BSI, 2011.

[8] Zheng J F, Luo J, Mo J L, Peng J F, Jin X S, Zhu M H. Fretting wear behaviors of a railway axle steel. Tribol Int 43(5-6): 906-911 (2010)

[9] Zhu C, He J, Peng J, Ren Y, Lin X, Zhu M. Failure mechanism analysis on railway wheel shaft of power locomotive. Eng Fail Anal 104: 25-38 (2019)

[10] Zhou Z R, Liu Q Y, Zhu M H, Tanjala L, Kapsa P, Vincent L. Investigation of fretting behaviour of several metallic materials under grease lubrication. Tribol Int 33 (2): 69-74 (2000)

[11] Pearson S R, Shipway P H, Abere J O, Hewitt R A A. The effect of temperature on wear and friction of a high strength steel in fretting. Wear 303(1-2): 622-631 (2013)

[12] Hayes E K, Shipway P H. Effect of test conditions on the temperature at which a protective debris bed is formed in fretting of a high strength steel. Wear 376-377: 1460-1466 (2017)

[13] Fu Y, Wei J, Batchelor A W. Some considerations on the mitigation of fretting damage by the application of surfacemodification technologies. J Mater Process Tech 99(1): 231-245 (2000) 
[14] Meng Y G, Xu J, Jin Z M, Prakash B, Hu Y Z. A review of recent advances in tribology. Friction 8(2): 221-300 (2020)

[15] Kovacı H, Hacısalihoğlu, Yetim A F, Çelik A. Effects of shot peening pre-treatment and plasma nitriding parameters on the structural, mechanical and tribological properties of AISI 4140 low-alloy steel. Surf Coat Technol 358: 256-265 (2019)

[16] Yetim A F, Kovaci H, Yildiz F, Bayrak O, Çelik A. The effect of post aging on wear properties of a plasma nitrided ferromagnetic steel under DC magnetic field. Wear 332-333: 988-994 (2015)

[17] Prakash N A, Bennett C J. The effect of plasma nitriding and post oxidation on fretting wear behaviour of a high strength alloy steel. J Phys Conf Ser 843(1): 012079 (2017)

[18] Kovacı H, Yetim A F, Baran O, Çelik A. Fatigue crack growth analysis of plasma nitrided AISI 4140 low-alloy steel: Part 1-constant amplitude loading. Mater Sci Eng A 672: 257-264 (2016)

[19] Kovacı H, Yetim A F, Baran, Çelik A. Fatigue crack growth analysis of plasma nitrided AISI 4140 low-alloy steel: Part 2-Variable amplitude loading and load interactions. Mater Sci Eng A 672: 265-275 (2016)

[20] Araújo E De, Bandeira R M, Manfrinato M D, Moreto J A, Borges R, Vales S D S, Suzuki P A, Rossino L S. Effect of ionic plasma nitriding process on the corrosion and microabrasive wear behavior of AISI 316L austenitic and AISI 470 super-ferritic stainless steels. J Mater Res Technol 8(2): 2180-2191 (2019)

[21] Wang M Z, Kang J J, Yue W, Fu Z Q, Zhu L N, She D S, Wang C B. Effects of combined treatment of plasma nitriding and laser surface texturing on vacuum tribological behavior of titanium alloy. Mater Res Express 6(6): 066511 (2019)

[22] Das K, Alphonsa J, Ghosh M, Ghanshyam J, Rane R, Mukherjee S. Influence of pretreatment on surface behavior of duplex plasma treated AISI H13 tool steel. Surf Interfaces 8: 206-213 (2017)

[23] Carrera-Espinoza R, Valerio A R, Villasana J D P, Hernández J A Y, Moreno-Garibaldi P, Cruz-Gómez M A, López U F. Surface laser quenching as an alternative method for conventional quenching and tempering treatment of 1538 MV steel. Adv Mater Sci Eng 2020: 7950684 (2020)

[24] Sun P, Li S, Yu G, He X, Zheng C, Ning W. Laser surface hardening of $42 \mathrm{CrMo}$ cast steel for obtaining a wide and uniform hardened layer by shaped beams. Int J Adv Manuf Technol 70(5-8): 787-796 (2014)

[25] Park C, Kim J, Sim A, Park I duck, Jang H, Chun E J. Influence of high-power diode laser heat treatment on wear resistance of a mold steel. J Mech Sci Technol 33(2): 829-836 (2019)

[26] Wang W J, Guo J, Liu Q Y, Zhu M H. Effect of laser quenching on wear and damage of heavy-haul wheel/rail materials. Proc Inst Mech Eng Part J J Eng Tribol 228(1): 114-122 (2014)

[27] Lesyk D A, Martinez S, Mordyuk B N, Dzhemelinskyi V V., Lamikiz, Prokopenko G I, Milman Y V., Grinkevych K E. Microstructure related enhancement in wear resistance of tool steel AISI D2 by applying laser heat treatment followed by ultrasonic impact treatment. Surf Coat Technol 328: 344-354 (2017)

[28] Wang H D, Ma G Z, Xu B S, Yong Q S, He P F. Design and application of friction pair surface modification coating for remanufacturing. Friction 5(3): 351-360 (2017)

[29] Fouvry S, Fridrici V, Langlade C, Kapsa P, Vincent L. Palliatives in fretting: A dynamical approach. Tribol Int 39(10): 1005-1015 (2006)

[30] Luo J, Cai Z B, Mo J L, Peng J F, Zhu M H. Torsional fretting wear behavior of bonded $\mathrm{MoS}_{2}$ solid lubricant coatings. Tribol Trans 58(6): 1124-1130 (2015)

[31] Luo J, Zhu M H, Wang Y D, Zheng J F, Mo J L. Study on rotational fretting wear of bonded $\mathrm{MoS}_{2}$ solid lubricant coating prepared on medium carbon steel. Tribol Int 44(11): 1565-1570 (2011)

[32] Li J, Yang X, Wang S, Wei K, Hu J. A rapid D.C. plasma nitriding technology catalyzed by pre-oxidation for AISI4140 steel. Mater Lett 116: 199-202 (2014)

[33] Salarizadeh P, Askari M B, Seifi M, Rozati S M. $\mathrm{MoS}_{2}$ coating on different carbonaceous materials: Comparison of electrochemical properties and hydrogen evolution reaction performance. J Electroanal Chem 847: 113198 (2019)

[34] Ji Y P, Liu Z C, Ren H P. Morphology and formation mechanism of martensite in steels with different carbon content. Adv Mater Res 201-203: 1612-1618 (2011)

[35] Zhang Y P, Li P P, Ji L, Liu X H, Wan H Q, Chen L, Li H $\mathrm{X}$, Jin Z L. Tribological properties of $\mathrm{MoS}_{2}$ coating for ultra-long wear-life and low coefficient of friction combined with additive $\mathrm{g}-\mathrm{C}_{3} \mathrm{~N}_{4}$ in air. Friction 9(4): 789-801 (2021)

[36] Yamashita T, Hayes P. Analysis of XPS spectra of $\mathrm{Fe}^{2+}$ and $\mathrm{Fe}^{3+}$ ions in oxide materials. Appl Surf Sci 254(8): 2441-2449 (2008)

[37] Zhou Y, Cai Z B, Peng J F, Cao B B, Jin X S, Zhu M H. Tribo-chemical behavior of eutectoid steel during rolling contact friction. Appl Surf Sci 388: 40-48 (2016)

[38] Koroteev V O, Bulushev D A, Chuvilin A L, Okotrub A V., Bulusheva L G. Nanometer-sized $\mathrm{MoS}_{2}$ clusters on graphene flakes for catalytic formic acid decomposition. ACS Catal 4(11): 3950-3956 (2014)

[39] Zhao J, He Y, Wang Y, Wang W, Yan L, Luo J. An investigation on the tribological properties of multilayer graphene and $\mathrm{MoS}_{2}$ nanosheets as additives used in hydraulic applications. Tribol Int 97: 14-20 (2016) 
[40] Zhu M H, Zhou Z R. An investigation of molybdenum disulfide bonded solid lubricant coatings in fretting conditions. Surf Coat Technol 141(2-3): 240-245 (2001)

[41] Pearson S R, Shipway P H. Is the wear coefficient dependent upon slip amplitude in fretting? Vingsbo and Söderberg revisited. Wear 330-331: 93-102 (2015)

[42] Lemm J D, Warmuth A R, Pearson S R, Shipway P H. The

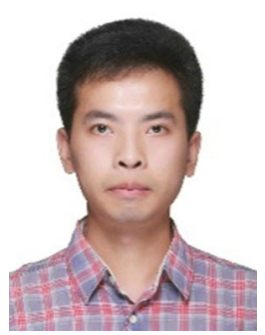

Jifan HE. He received his bachelor's degree in mechanical engineering in 2015 from Northwest Agriculture \& Forestry University, Xi'an, China. He is currently pursuing his Ph.D. at

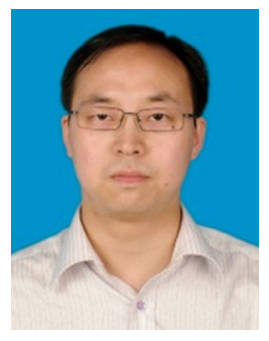

Zhenbing CAI. He received his Ph.D. degree in materials science from Southwest Jiaotong University, China, in 2009. He joined the Mechanical Engineering School at

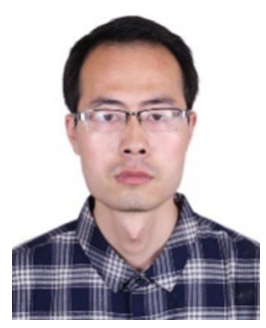

Yanping REN. He received his bachelor's degree in mechanical engineering in 2015 from the Mechanical Engineering School at Southwest Jiaotong University.

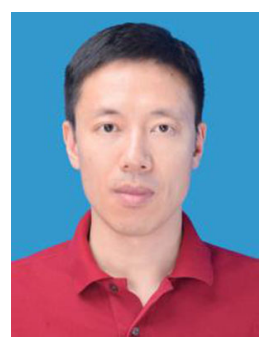

Jinfang PENG. He received his bachelor and Ph.D. degrees from Southwest Jiaotong University, Chengdu, China, in 2006 and 2012, influence of surface hardness on the fretting wear of steel pairs-Its role in debris retention in the contact. Tribol Int 81: 258-266 (2015)

[43] Su C R, Shi L B, Wang W J, Wang D Z, Cai Z B, Liu Q Y, Zhou Z R. Investigation on the rolling wear and damage properties of laser dispersed quenched rail materials treated with different ratios. Tribol Int 135: 488-499 (2019)

the Tribology Research Institute, Southwest Jiaotong University. His research interests include fretting tribology and the development of fretting apparatus and electromechanical equipment.

Southwest Jiaotong University from 2009. His current position is a professor and the director of the Tribology Research Institute. His research areas cover the tribology of electrical contact systems, aviation, and nuclear power equipment.

Recently, he is a Ph.D. candidate at the Tribology Research Institute at Southwest Jiaotong University. His research interests include fretting wear, fretting fatigue, and testing equipment development.

respectively. He is currently an associate professor at Traction Power State Key Laboratory, Southwest Jiaotong University. His research interests are focused on fretting fatigue and engineering failure analysis. 


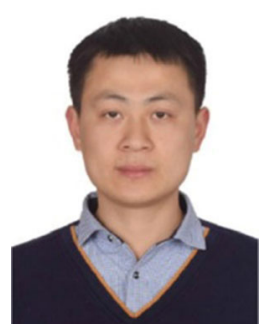

Jianhua LIU. He received his bachelor and Ph.D. degrees from Southwest Jiaotong University in 2010 and 2016, respectively. He is

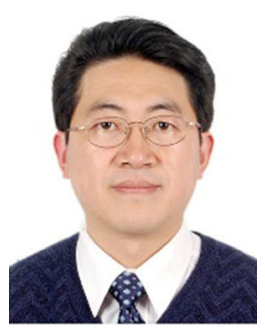

Minhao ZHU. He received his bachelor and master degrees from Southwest Jiaotong University, Sichuan, China, in 1990 and 1993, respectively. Since then, he has been working at Southwest Jiaotong University. From 1996 to 2001, he currently an associate professor at the School of Materials Science and Engineering, Southwest Jiaotong University. His research interests include friction, wear, and design of fastener connections.

pursued his Ph.D. from Southwest Jiaotong University, Sichuan, China. His current position is a professor, doctoral supervisor, and dean of the School of Materials Science and Engineering. His research areas cover fretting wear, fretting fatigue, surface engineering, and design of fastener connections. 